\title{
The Social and Economic Challenges of the Namibian Children of the Liberation Struggle at Berg Aukas Camp in Grootfontein, Otjozondjupa Region
}

\author{
Dorthea Nanghali Etuwete Shiningayamwe1, Rakel Kavena Shalyefu², \\ Alex Tubawene Kanyimba ${ }^{2}$ \\ ${ }^{1}$ Department of Recognition of Prior Learning, Namibia Training Authority, Windhoek, Namibia \\ ${ }^{2}$ Department of Life-Long Learning and Community Education, University of Namibia, Windhoek, Namibia \\ Email: shietuwete@gmail.com, rkshalyefu@unam.na, akanyimba@unam.na
}

Received 25 February 2014; revised 26 March 2014; accepted 2 April 2014

Copyright (C) 2014 by authors and Scientific Research Publishing Inc. This work is licensed under the Creative Commons Attribution International License (CC BY). http://creativecommons.org/licenses/by/4.0/ (c) (i) Open Access

\begin{abstract}
Despite efforts to address the economic challenges and provide a social safety net for orphans and vulnerable children, Namibia is still faced with social and economic challenges. The aim of this study is to explore the developmental context that underpins the social and economic challenges of the Namibian children of the liberation struggle at the Berg Aukas camp in Grootfontein in the Otjozondjupa Region. Data were collected by means of in-depth interviews with the Namibian Children of the Liberation Struggle and analysed by means of a case- and content-oriented analysis. The results of the study show that Children of the Liberation Struggle are faced with social and economic hardships. The social hardships include dropping out of school, teenage pregnancies and traumatic events such as illness, stigma and discrimination, isolation and loneliness, poor family structures, and lack of adult support and guidance. The economic hardships relate to lack of financial assistance to further their studies and follow aspired careers. The socio-economic challenges refer to lack of social support, lack of counseling, lack of personal income to sustain career development and unfamiliarity with Namibian government policies. The study recommended psychosocial counselling and re-orientation of supportive policies that would provide social safety nets for these children.
\end{abstract}

\section{Keywords}

Economic; Social Challenges; Namibian Children; Vulnerable Children; Liberation Struggle 


\section{Introduction}

Namibia is one of the largest countries situated on the south-western coast of Africa [1]. Destabilisation, war and the policy of apartheid imposed on Namibia by the governments of Germany and South Africa respectively between 1884 and 1990 had a negative social and economic impact on the lives of Namibians because it caused extreme poverty and social displacement [2]. The efforts taken by the new Namibian government that was formed on 21 March 1990 entailed a radical national programme to reverse the effects of apartheid, destabilisation and war through national policies and affirmative action programmes.

The context of Namibia's social and economic transformation efforts is described in the Namibia Vision 2030, a long-term policy document for national development, which was published in 2004. The Namibia Vision 2030 hopes to create a "prosperous, industrialised Namibia, developed by her human resources, enjoying peace, harmony and political stability" [3]. Prior to the Namibia Vision 2030, the context of Namibia's economic and social transformation was being pursued through the "National Development Plans (NDPs, 1, 2, \& 3) and the National Budgetary Framework” [4]. Currently, the Namibia Vision 2030 is being implemented through a medium-term document for national development, called NDP 4.

Since the independence of Namibia, social and economic transformation has been observed. The Bank of Namibia’s ninth Annual Symposium Publication reports that economic development is respectable in Namibia although volatile. It states further that Namibia is one of the very few countries in Sub-Saharan Africa that maintains a social safety net for the elderly, the disabled, war veterans, orphans and vulnerable children [4]. Despite the plans and strategies in place, Namibia is still being challenged by social and economic problems [4]-[6]. These challenges deserve attention, because they will re-emerge time and again in national policies which endeavour to reverse the injustices of apartheid, destabilisation and war.

Against the backdrop succinctly described above, the aim of this study was to investigate the developmental context that underpins the social and economic challenges of the Namibian Children of the Liberation Struggle (CLS) from 1990 until 2008. To achieve this aim, the background is sketched first by referring to Namibian colonial history and the efforts of the Namibian government to address the plight of the Namibian CLS. Thereafter the problem and research questions being addressed are unpacked. This is followed by a theoretical framework, in which the key concepts and theory that form the thrust of the study are elucidated. The research methods, strategies and design are explained, as well as how the narrative and case-oriented design were operationalised in the study. The data are then presented and interpreted, applying the ecological theory of child development. The CLS narratives depict development context that underpins the social and economic experiences at different levels of the ecological systems theory of child development. The emerging themes are discussed and measures to be taken are suggested to improve the plight of the CLS. The implication of the results of the study towards the government policies targeting the CLS is explained.

\section{Background of the Study}

Namibia led a liberation struggle against the German colonial occupation from 1884 to 1914 and the South African colonial occupation from 1915 to 1990 [7] [8]. The authorisation to end Namibia's foreign occupation and domination was issued by the United Nations (UN) Security Council Resolution 435 in 1978, implemented on 1 April 1989 and supervised by the United Nations Transition Assistance group (UNTAG) [9]-[12]. This period marked an important milestone in Namibian history, because about 43,000 exiled Namibians were repatriated to their motherland. This repatriation included children who were born in Cuba, Yugoslavia, Czechoslovakia, Angola, Germany, Zambia, Tanzania and Zambia or raised in these countries by exiled soldiers and refugees of the liberation struggle [13].

Since their arrival in Namibia, the CLS have been given various names, such as "SWAPO Kids", "Struggle Children”, “Exile Kids” and "Returnees Children” [14] [15]. In 2008, the so-called Exile Kids made national headlines by gathering in huge numbers country-wide to demonstrate, calling for the Government of the Republic of Namibia (GRN) to take note of their plight and heed their complaints. They demanded identity documents, jobs and employment, better educational opportunities, vocational training, and financial assistance to improve their social and economic conditions. In response to the plight of the so-called Exile Kids, the South West Africa Peoples' Organisation (SWAPO), led by the GRN, took a Cabinet Decision, No. 17/16.09/002, to use the term "Children of the Liberation Struggle" (CLS) to refer to the Exile Kids [10]. The same Cabinet Decision included the establishment of a joint ministerial committee. The Ministry of Youth, National Service, Sport and Culture 
(MYNSSC) was tasked to chair and direct the registration process of all the CLS and address their demands.

The Namibian government has put in place efforts intended to address the social and economic plight of the Namibian CLS, supported by the Namibian Exile Kids Association (NEKA), whose mission it is to engage the Namibian government in the recruitment process of the Namibian CLS and to address all their needs by reintegrating them into society as productive and proud citizens, considering their unique diverse needs and circumstances. Despite these social arrangements, some of the Namibian CLS continue to camp illegally in Windhoek and in various parts of Namibia, irrespective of transportation arrangements and promises to attend to their plight [4] [16] [17]. The thrust of this study is to trace the developmental context of the associated socio-economic challenges encountered by the Namibian CLS who have been camping at Berg Aukas since November 2011. In particular, it focuses on the Namibian CLS born and raised in Angola, Czechoslovakia, Sierra Leone, Cuba, Zambia and Russia, because existing literature on Namibian CLS focuses more on the socio-economic experiences of children from the German Democratic Republic (GDR), with a lesser focus on the socio-economic experiences of CLS from the above-mentioned countries.

\section{Statement of the Problem}

The Namibian CLS have been demonstrating and camping at the Ministry of Veteran Affairs in Windhoek and at several SWAPO offices country-wide since 2008. They have been demanding job opportunities, better educational opportunities, identity documents, financial assistance to start businesses and re-integration into Namibian society [18]. The Newspaper reported that Exile Kids took issue with the government for allegedly not catering to their needs, as some of them were orphaned when their parents died in exile during the country's liberation struggle [18]. The reporter further referred to the CLS's behaviour as a serious public concern and labelled them "spoiled and undisciplined kids". Therefore, the research problem being investigated in this study rests on the developmental context that underpins the social and economic challenges of the CLS. The following research questions were developed to address the research problem:

- What are the social challenges of the Namibian CLS at the micro-level stage of child development?

- What are the social challenges of the Namibian CLS at the meso-level stage of child development?

- What are the social and economic challenges of the Namibian CLS at the exo-level stage of child development?

- What are the economic and economic challenges of the Namibian CLS at the macro-level stage of child development?

- What are the social and economic aspirations of the Namibian CLS?

- How do the Namibian CLS plan to address their social and economic challenges?

\section{Theoretical Framework}

The concepts "social” and "economic" and the "Namibian Children of the Liberation Struggle” are resurfacing in Namibia's current national development issues. The term social challenges refer to an array of procedural difficulties that the Namibian CLS face in the family, community and broader public environment. These challenges include poverty, health problems, inequality and lack of educational opportunities [19] [20]. The economic challenges refer to the array of pecuniary difficulties faced by the Namibian CLS. These are categorised into financial support, individual income and unemployment [19]-[21]. The Namibian CLS are defined according to the Veteran Act, Act no. 2 of 2008, as inclusive of the exiled children who until 21 March 1990 were under the age of 18 years [10].

The theoretical framework that we found appropriate by which to study the social and economic challenges of the Namibian CLS at Berg Aukas, Grootfontein, Otjozondjupa Region, is the child development theory formulated by Urie Bronfenbrenner, also known as the "Theory of the Onion" because it has many interdependent layers [22]-[24]. If one layer of the onion rots over time, the whole onion will eventually be affected. It outlines that no child is an island and isolated; every part of the societal system is crucial and may be affected by another part [24].

The Bronfenbrenner theory views the developing child as embedded in a series of complex and interacting systems [25] [26]. There are four levels or contexts or systems that influence child development, namely the micro-system, meso-system, exo-system and macro-system [24] [25].

- The inner circle or micro-system consists of people or objects in a child's immediate environment. These in- 
clude parents, extended families, neighbourhood, church or religious settings, teachers, pastors, friends. The family is the first world in which children experience a pattern of activities, roles and interpersonal relations. Some children are raised in loving families whereas others are raised in unloving families.

- The middle or in-between circle called meso-system is a relationship and contact between the micro-systems and meso-systems. It includes the ways in which family and school connect to one another, the family experiences and peer experiences. Children who are rejected during their upbringing may have difficulty developing positive relations with the wider society.

- The outside circle or exo-system refers to a social setting that a child may not experience first-hand but which still has influence on that child. For example, a mother's work environment or decisions taken by community leaders.

- The societal circle or macro-system refers to the broader environment in which the child grows up, specifically to the subculture and culture in which the micro-system, meso-system and exo-system are embedded. These may include the country's policies and laws, cultural beliefs, customs, and international ideologies (based on Rochat, Hough, Mitchel \& Jewitt, [23]; Louw \& Louw, [24] Mcilveen, et al. [25]

The Bronfenbrenner theory of child development is used to explain how the micro-, meso-, exo- and macro-environments underpin the social and economic challenges of the Namibian CLS. The relationship between the child, family and the community contributes positively to the child's development in the same way as the child's membership contributes to a cultural group that values excellence [24] [26].

\section{Research Design, Strategies and Methods}

This study adopted a qualitative research method, because it seeks and explores diverse human lived experiences, views and personal positions [27]. This method relies on written or spoken words or observations that do not have direct numerical interpretations [28].

The study used a combination of case study and narrative research design [29] [30]. Case study designs are useful in exploring topics where previously little knowledge or understanding existed [29]. The narrative research design was used to facilitate the process during which the respondents (CLS) tell their real socio-economic life stories, "using time sequences or chronology of events" [31] to explore how these contributed to their present lives, their identities and the reality of their life stories [31].

\subsection{Population and Sampling}

The population of the study was the Namibian CLS in the Berg Aukas camp, Grootfontein, in the Otjozondjupa region under the MYNSSC's care during November 2011. These children were selected because they reside in the same location where one of the researchers is a staff member.

The sampling procedure was both purposeful and convenient. It assisted in identifying respondents who were information-rich and who possessed the most representative characteristics or typical attributes that best served the purpose of the study [31].

The researchers compiled an inventory sheet to note certain characteristics of respondents such as age, gender, placement in orphanages, country of birth, region of origin, parental care, and highest qualification. The purpose of the inventory sheet was to provide a balance of the above-mentioned characteristics in the sample. The study thus targeted 15 respondents; but some of those who initially agreed to be interviewed, ultimately did not completely meet the inventory criteria in terms of country of birth or exile. In the end, 14 stories were selected for analysis. All the narratives contain the reality of these children's life stories.

\subsection{Data Collection Process and Analysis}

The data was collected from CLS at the Berg Aukas camp, Grootfontein from 14 - 27 November 2011. Permission to access Berg Aukas camp was sought from the MYNSSC Permanent Secretary, the Head of the Centre at Berg Aukas and the Camp Commander. Before the researchers collected the data, the Head of the Centre at Berg Aukas introduced them to the Camp Commander, Captain, Sergeant and other senior officials working with CLS in the camp. The Camp Commander in turn introduced the researchers to the CLS at the parade and briefed the children about the goals and objectives of the study.

In addition, permission to conduct face to face interviews was obtained from the respondents by them signing 
a consent form that promised them confidentiality and anonymity. A voice recorder was used to capture the discussions. At the beginning of interview sessions a separate private room was used to maintain confidentiality. Interviews were conducted in participants' indigenous languages and were later translated into English. During the first stage of data collection, the researchers won the trust and honesty of the CLS by building closer relationships and rapport. The activities involved were: driving to Grootfontein (20 km from the Berg Aukas camp) in the morning to do window-shopping with participants, accompanying them to social events in the evening and participating in some activities within the camp. The researchers distributed informed consent forms to each of the CLS and explained the goals and objectives of the study.

All raw data from the voice recorder was transcribed as narrated by respondents and analysed using caseoriented and content analysis [32]. Case-oriented analysis entails "writing a case study report to allow the reader to understand the case as unique, a holistic entity, and an idiosyncratic manifestation of the phenomena of interest” [33]. Qualitative content analysis is the process of identifying, coding, and categorising the primary patterns in the data. Coding is the process by which patterns, words and meanings in the data are identified and categorised [32]-[34].

\section{Presentation and Interpretation of Results}

The transcribed data from the Namibian CLS narratives was arranged into themes and patterns following the four levels of child development mentioned previously. These four levels of child development theory address the research questions stated earlier.

\subsection{Social Challenges of the Namibian CLS at the Micro-Level Stage of Child Development}

The social challenges of the Namibian CLS at micro-system level were studied and the following patterns emerged in the corpus of their narrative interviews:

Case one: "Meekulu" (Grandmother) was a wonderful woman. She loved me and had so much respect for me. She was fun, generous, and courageous and had a woman's heart indeed. "Meekulu" was not only loving and supportive but also very hardworking as she worked hard in the field to ensure that we all had food to eat (mahangu porridge mainly). I would be at school but "Meekulu” would; call me to help her out with her pension logistics, because she trusted me and treated me very nice. She was my reason to wake up every morning. She had a lot of passion for her grandchildren, and for that reason, I settled in very well with her and my new-found family in Namibia. May her soul rest in peace. (Female, 32 years, 12 November 2011).

Case two: "Later on, I also realised that 'Meekulu' hated my mother and maybe for that reason, the resentment passed on to us too. 'Meekulu' always treated my little sister and me differently from the rest of her grandchildren. She was very hostile and would often say demeaning things to my mother, even in our presence. She would scream at my mother saying things like: 'You shikumbu (you whore,) you have brought shame and misfortune into my house, you discredited my whole family. Go back to where you came from and take your bastard children with you; go back to being the cheap slut that you have always been in Angola or wherever you were.' 'Meekulu' had so many negative feelings against me. She would frankly tell me that I am not her genuine grandchild: 'Kandi na sha iitekulu yaambwela ngaye' (I have no weird strange and outcast grandchildren), 'Omapuli nga geya megumbo lyandje muka' (These so-called terrorists that ended up in my house should all go back to their life in the bush). (Female, 27 years, 25 November 2011)”.

Case three: "We were very close to 'Meekulu,' she was more of a good friend to me, until she fell ill and sadly passed away. She died in my own arms in the morning of that fateful day. After her death, everything started to slowly fall apart, and keeping some sort of order in the house started to become a challenge. My family would treat me so badly at times I would wish that I had died with 'Meekulu'. It was not too long after her death that one after the other older family members (including my mother) slowly started to move away, leaving me with the responsibility of looking after my younger cousins. They all left the house with an excuse that they were going to look for work and would hopefully return with money to give us a better life. The loss of 'Meekulu' not only signified the beginning of my hardships but it also caused my incon- 
sistent attendance of school.” (Male, 28 years, 18 November 2011).

Case four: "At an early stage of living in my new Namibian home, I suddenly realised how I was never going to be considered part of the family. It seemed as though everybody in the house hated me, I was labelled an outcast, an intruder and my housemates bullied me so much that one could think that their life depended on it. 'You are not a Namibian, you are from Angola, go back to where you belong and came from,' they would constantly say that to me. They never understood how I felt; thinking back to my past, the name-calling and all the hurtful remarks they had ever said to me remain fresh in my memory and it hurts me very much to this very day. Even elders at the village had labelled me as an outcast; to them I was nothing more than 'Omumbwela' (foreigner) who had no manners. They had so many xenophobic feelings towards me. They all disliked me for the mere fact that I was born in Angola. I was very young and it was a very sad experience. I had no sense of belonging, I felt as though I had no place in the family, much less in society, in Namibia or the world. I lived without peace and thinking nobody ever loved me. I feel insecure and all alone in the world even to this day; I can say I have seen worries in my life. Emotional wounds have been inflicted on me and they will never heal. There was no counselling, nor support to integrate me into society.” (Female, 25 years, 13 November 2011).

The above excerpts indicate that the person closest to the CLS in their micro-environment was the grandmother. This came about due to the death of their biological mothers resulting from war during the colonial occupation. However, the above excerpts show that the CLS were ambivalent towards their grandmothers. They viewed her as a source of care and social support but also harboured elements of hostility and resentment. It also affirms that the Namibian CLS's social experience at the micro-level was characterised by stigma, isolation and discrimination.

\subsection{The Social Challenges of the Namibian CLS at the Meso-Level Stage of Child Development}

Once the micro-system was uncovered, we proceeded to establish the CLS's social experiences at the mesolevel. These are portrayed in the following narratives:

Case five: "I did not go to school until the age of 12 years. When I enrolled in grade one in Namibia I was 13 years old. I lived in depression and I was very distressed. I was in grade 9 when my health started to deteriorate, I got so sick that I would faint and collapse at school. I was always in and out of hospitals. Despite my sickness, my mother would still yell and scream that I am a lazy fool in her house. I started experiencing terrible chest pain and that caused me to stay out of school so many times. My school performance drastically dropped. Teachers at school detected my problem and they encouraged me to keep going. When I survived the mysterious illness, it was too late to go back to school; I came back to the village from the hospital. Despite a referral letter from the hospital confirming that I left school because of illness, the principal ignored me, arguing that I was over the age-limit to study for my grades. That is how I ended up in grade 9. Not long after that I turned into a village home girl. I became pregnant and my mother rejected me throughout my pregnancy.” (Female, 32 years, 12 November 2011).

Case six: "Ever since I started school, I never had a choice of attending school without interruption. Firstly, 'Meekulu' kept me out of school for three whole years for the mere reason that I could not speak Oshindonga. She always went on, 'Kosikola itoyi ko ngwee kushi okupopya Oindonga koosikola ihakuyi aambwela ha ya popi oimbalantu, oto ti owu li Kombalantu?’ (Do you think that you will be sent to school while you do not know how to speak Oshindonga?) (Oshidonga is my mother’s dialect while Oshimbalantu is my late father's dialect). 'School learners are not outcasts like you, who are even unable to speak your mother's dialect, Oshindonga, but instead speak Oshimbalantu. Do you think you are in Ombalantu?' Secondly, when my 'Meekulu' had marital problems with my grandfather and later separated/divorced, we relocated from Eloolo to Oshigambo. Unfortunately, the family crisis happened during midyear, subsequently I was forced to drop out of school before completing the academic year. I enrolled and repeated the very same grade. Thirdly, I lost my way in life as I had no form of parental guidance and I made the worst choice a 14 year-old teenage girl could ever make by falling pregnant and sadly I lost the baby at a very tender age. I finally dropped out of school in grade nine.” (Female, 31 years, 19 November 2011). 
In the above excerpts the CLS' social experiences pertaining to education and health are shown. The CLS started school late, were denied educational opportunities and had their school careers interrupted because of illness, teenage pregnancy and home breakdowns. The CLS social experiences at meso-level were characterised by lack of social support and counselling opportunities. These manifested in teenage pregnancies, school attendance at a late age and home breakdowns.

\subsection{The Economic Challenges of the Namibian CLS at the Exo-Level Stage of Child Development}

The economic challenges of the Namibian CLS were identified. The following experiences emerge from their narratives:

Case seven: “...Since our home turned into a child-headed one after the death of my 'Meekulu', it forced me to drop out of school after my mid-year exam in grade eight. When I moved to my father's place the following year, although I was enrolled in grade eight at Iidangungu Combined School, I can honestly say that perhaps my father never understood the importance of education, because he was an uneducated man himself. He never paid for my school fees nor bought me a school uniform. He would rather send me to the cattle post, because all he cared about was the well-being of his cattle. He would go on leave and travel with me to the cattle post for weeks. My teachers always reprimanded me for staying away from school and classes and told me to stick to school. My father, however, never paid heed to my school commitments. On several occasions, teachers ordered my parents to visit the school because of my low school attendance habit. Nobody cared enough to show up, it was very difficult to keep up with school and I had nobody to turn to for support. (Female 31 years, 19 November 2011).

Even though I never gave up and tried selling firewood by the roadside, I later joined a group of teenage thugs; we smoked and abused alcohol at a very tender age, we even robbed people to pay for our school fees in our home town. It was not easy to make it in school; I succumbed in grade 10 and never got the chance to register at NAMCOL. I later left school completely, I had given up on my hopes and dreams and I felt worthless. I had lost all hopes of becoming someone in society, if only 'Meekulu' (Grandmother) was alive”. (Male, 28 years, 18 November 2011).

The excerpts above demonstrate the economic challenges faced by the Namibian CLS. The hardships exposed them to becoming school drop-outs, and abusing drugs and alcohol. These economic hardships can be attributed to several factors, including their grandparents being unemployed, lack of funds to finance the education of vulnerable groups and being unaware of Namibian government policies, which allow learners from disadvantaged backgrounds to enrol in school without paying or contributing to school development funds.

\subsection{The Socio-Economic Aspirations of the Namibian CLS}

The aspirations of the Namibian CLS were identified. An aspiration refers to a strong desire to have or to do something. In the context of this study aspirations relate to the desire to have an education, a job, to be healthy and to have social status. The following narratives express the socio-economic aspirations of the Namibian CLS:

Case eight: "I am confident about my dream of becoming a social worker or a pastor. I enjoy counselling and helping others with problems. I wish to own a crèche or a kindergarten, unite all orphans and vulnerable children in my family and give them the best. I cry aloud to the government to allocate a piece of land for me to start a new life with my children. I pray to God to get a job to support my kids. I am pleading with the government to give me a place to stay, to cultivate and do my work on my land". (Female, 32 years, 12 November 2011).

Case nine: "I really loved going to school and I still dream of becoming a Business Administrator, even though I only ended up with grade nine. My inconsistent school attendance started when I was in grade six at Mandume Primary School in Windhoek. When my father and my stepmother had marital problems, they expelled me to the North during the April/May holiday, never to come back. I packed my bags and left to go to my 'Meekulu's' homestead in Ogongo. It was so sad, nobody sent me back to school, so I stayed 
home that whole year without completing my grade six. My stay at Ogongo was very challenging, I was more of a foreigner and the xenophobic feeling was very strong in the house. Both physical and emotional abuse worsened with each passing day and I became extremely unhappy and stressed. In September 2004 when I was in grade nine I left school for good when I was left with no choice but to move from Ogongo to Oukwanyama to my late (paternal) 'Meekulu’s’ house’. (Female, 27 years, 25 November 2011).

Case ten: "I am 28 years old; definitely, my parents will not listen to my plea to send me back to school. If only the government could fund my studies. I am talented and brilliant in technical and practical knowledge. I dream of owning a motor vehicle garage in the future. I wish to be given an opportunity to go back to school and study engineering or motor mechanics.” (Male, 28 years, 18 November 2011).

Case eleven: “...Even though my life was so difficult, I still have my dreams because I have learnt that they are something that cannot be taken away from me. I am confident that I am a valuable person in society, though many people consider me worthless. I am still keeping my dream of someday going back to school and working, saving a few cents and furthering my studies. I would like to do cosmetology to advance my theoretical knowledge in hairstyling, beauty treatment, make-up art, pedicures and manicures. My two major wishes are to run a beauty and cosmetic business or become a pilot or a priest.” (Female, 22 years, 20 November 2011).

The excerpts above indicate that the Namibian CLS had aspirations in life. These include careers in social work, or becoming a pilot, priest, businessman or woman, beauty therapist and motor mechanic. However, several factors prevented them from entering these noble professions, among others social breakdown at home, lack of educational opportunities and lack of financial support. The conclusion that can be made is that intervention in these areas could have helped to reverse the negative trend among the Namibian CLS.

\subsection{How the Namibian CLS Planned to Address the Socio-Economic Challenges at Macro-Level: Policies and Laws}

The Namibian CLS planned to address their own social and economic plight. The following forms the corpus of their narratives on how they planned to address the socio-economic challenges at macro-level:

Case twelve: "Thank God there was a demonstration of CLS that gave me peace of mind. I have nowhere where I belong. When I am at my mother's house, my heart does not feel happy and accepted. During the CLS demonstration we learned to accept one another as brothers and sisters in the forest; we shared experiences, problems and felt very much at ease with one another.” (Female, 32 years, 10 November 2011).

Case thirteen: "I am happy that we demonstrated. I never had a peaceful place that I could call home. My life has been in chaos, if it were not for the demonstration of CLS, I would not know how my life was going to be. It really rescued some of us and gave us peace. Staying at Berg Aukas camp made me very strong after sharing our hurtful experiences with other CLS; it relieved my stress and reduced my level of anxiety and depression.” (Female, 22 years, 22 November 2011).

Case fourteen: "The CLS demonstration gave me peace of mind; after sharing our challenges and experiences we learnt to accept and love one another. I shall say that being a CLS of Namibia is a challenge that I fought on my own and the struggle is not yet over”. (Female, 28 years, 19 November 2011).

The above narratives show that the Namibian CLS became aware of the importance of taking part in a demonstration. For them the demonstration created a social bond amongst themselves, gave them peace of mind and relieved them of stress. It can be concluded that the Namibian CLS demonstration created an enabling environment for them to share their painful moments, but it also gave them an opportunity to embrace themselves, support, comfort each other and get connected to one another.

\section{Discussions}

The Bronfenbrenner ecological theory of development maintains that children are influenced by the proximal and distant environments [34] [35]. The above narratives indicate that the Namibian CLS were cared for by "Meekulu” which literally means "Grandmother”. The financial status of the Meekulu was also poor and this 
made it difficult for her to fend for these children. The Namibian CLS struggled to define who they were, where they belonged and what defined them in their lives. Children without any proper sense of an own identity remain ignorant of what they really want to do in life and are rather unsure of themselves [36]. They feel out of place, socially, and believe that they are insignificant and unimportant, not only from their own point of view but also as perceived by society [23].

The results of the study show that the Namibian CLS faced social and economic challenges. The social hardships included being school drop-outs, experiencing teenage pregnancy and traumatic events such as the illness and deaths of their "Meekulu". The other challenges were stigma and discrimination, isolation and loneliness, poor family structures, lack of adult support and guidance. The economic hardships relate to lack of funds to support their education and aspirations to follow careers.

It appears that the economic hardships experienced by the Namibian CLS forced them out of the labour market. One study has shown that failure to integrate young people into the labour market is caused by lack of education, health, and sources of household income [37]. Secondly, the narratives show that the Namibian CLS seemed to be unskilled and unemployable, because their level of education was noticeably low. This finding is confirmed by other empirical studies which show that qualification and experience have an impact on the employment level of young people [37]. Furthermore, it is also expressed in empirical literature that unemployed youth are condemned to long-lasting depression should they fail to turn their theoretical knowledge into practical ability, gain skills and improve their professional competence [37]. In light of the above, it is concluded that the unemployment situation of young people might result in depression and hopelessness. It is further concluded that any programme that addresses the plight of the Namibian CLS needs aggressive education, skills development and psychological support.

The results obtained show that Namibian CLS addressed their socio-economic challenges. The main method used was to engage in a demonstration. It seems that the Namibian CLS demonstrations country-wide, including the one at Berg Aukas, not only created an enabling environment for them to share their painful moments but also gave them an opportunity to embrace themselves, support, comfort each other and get connected to one another. However, they also noted that the demonstration was one of the first steps towards addressing their social and economic plight.

\section{Recommendations and Policy Implications}

The following recommendations are made:

- The Namibian CLS are in need of clinical support, trauma-healing sessions and counselling, because they were victims of stigma, isolation and depression. The GRN, NGO, NEKA and other partners need to provide mechanisms and opportunities for clinical counselling to address the traumatic and depressing effects that result from the socio-economic challenges the Namibian CLS.

- The provision of assistance for Namibian CLS, such as job, education and vocational training and business opportunities, should be based on social and economic circumstances. There is a need to establish a standardised recruitment template that should guide stakeholders in providing assistance to Namibian CLS.

- There is a need to educate Namibian society to create a conducive and friendly environment to allow the integration of the Namibian CLS as full and equal Namibians and to get rid of the negative perceptions which paint Namibian CLS as unruly and undisciplined. Media campaigns through the radio and NGOs also need to be engaged to address these matters.

The results of this study can help stimulate debate in the GRN about policies and acts that could integrate the Namibian CLS into the socio-economic system. It is important to review the Veteran Act so that it can provide social safety nets for vulnerable children residing at Berg Aukas and other camps. The Veteran Amendment Act of 2013 does not include the CLS and those veterans who died before being recognised as veterans. It only caters for dependants of the veterans who died after having been recognised [38]. This current state of affairs needs to be changed to enhance and address the socio-economic challenges of the Namibian CLS whose parents died in exile, so that their integration into the community is regulated.

Finally, this study postulates the need for a long-term strategy to address the socio-economic challenges facing the Namibian CLS. It is important that education and research institutions establish continuous evaluation of potential attitudes and behavioural changes of the Namibian CLS. Therefore, it is also important to conduct evaluation studies after two years of the policy implementation to determine the impact over a longer period. 


\section{Conclusions}

This article has addressed the social and economic challenges of the Namibian CLS. The authors of this document sought to answer the following research questions: 1) What are the social challenges of the Namibian CLS at the micro-level of stage of child development? 2) What are the social experiences of the Namibian CLS at the meso-level stage of child development? 3) What are the economic experiences of the Namibian CLS at the exo-level stage of child development? 4) What are the socio-economic aspirations of the Namibian CLS? And 5) How do the Namibian CLS plan to address their socio-economic challenges at the macro-level?

The answers to the research questions seem to suggest that the social and economic challenges of the Namibian CLS are rooted in a deeper social foundation relating to their upbringing and will not go away in the absence of a long-term strategy that should be integrated into the culture of the entire Namibian community. It seems that the Namibian CLS raised in Angola, Czechoslovakia, Sierra Leone, Cuba, Zambia and Russia were not provided with social support to deal with the transition from life in the camps during the liberation struggle to life in an independent Namibia. It is also important that the social experience and behaviour of the Namibian CLS residing at Berg Aukas be understood in the context of their low educational level and lack of parental support and guidance. The narratives pertaining to the social and economic challenges as well as aspirations from the Namibian CLS perspective implicitly document this scenario.

It is not a clear-cut assignment to address the social and economic challenges of the Namibian CLS. We have recommended the delivery of appropriate interventions, educational facilities and opening of various policies to address the reintegration of the Namibian CLS into society. It is important that NEKA engages not only the government but also the NGOs and the corporate sectors residing in Namibia to deploy clinical psychologists, sociologists, educationists and economists who could help address the social and economic challenges as well as the trauma and depression of the Namibian CLS.

\section{References}

[1] Kanyimba, A.T. and Coetzer, I.A. (2011) The Integration of Sustainability Education in Namibian Colleges of Education. Africa Education Review, 8, 133-147. http://dx.doi.org/10.1080/18146627.2011.586157

[2] Kössler, R. (2000) From Reserve to Homeland: Local Identities and South African Policy in Southern Namibia. Journal of Southern African Studies, 26, 447-462. http://dx.doi.org/10.1080/713683582

[3] Government of the Republic of Namibia. Namibia Vision 2030 (2004) Policy Framework for Long Term National Development. Office of the President, Windhoek.

[4] Fleermuys, F., Nakusera, F., Shangula, F. and Steytler, J. (2007) Broad-Based Economic Empowerment: Experience from Other Developing Countries. Bank of Namibia's $9^{\text {th }}$ Annual Symposium Publication, Windhoek. https://www.bon.com.na/CMSTemplates/Bon/Files/bon.com.na/80/808575c9-88e9-441b-9ce1-428b188a0644.pdf\#page=18

[5] Haugh , W.A. (2009) A Luta Continua: Coping with Threats to Prosperity and Health in Post-Independence Namibia'. Journal of Southern African Studies, 35, 99-113. http://dx.doi.org/10.1080/03057070802685593

[6] Krugmann, H. (2001) Fundamental Issues and the Threats to Sustainable Development in Namibia. Directorate of Environmental Affairs, Ministry of Environment and Tourism, Windhoek. http://wwwisis.unam.na/hivdocs/UNICEF/Namibia/Socioeconomic/DEA rdp 00462002 Fundamentals\%20sustainab le\%20development.pdf

[7] Amoo, S.K. and Harring, S.L. (2009) Namibian Land. Law, Land Reform and Restricting of Post-Apartheid Namibia. University of Botswana Law Journal, 9, 87-122.

[8] Angula, N. and Lewis, S.G. (1997) Promoting Democratic Decision Processes in Educational Decision Making: Reflections from Namibia's First Five Years'. International Journal of Educational, Development, 17, 223-239. http://dx.doi.org/10.1016/S0738-0593(96)00079-X

[9] Melber, H. (2003) From Controlled Change to Changed Control. The Case of Namibia. Journal of Contemporary African Studies, 21, 267-284. http://dx.doi.org/10.1080/02589000305441

[10] Ministry of Youth, National Service Sport and Culture (2010) Abridged Narrative Report of the Verification Task Team on the Registration and Verification of the Plight for the Children of the Liberation Struggle. Unpublished Report, Windhoek.

[11] Olsson, L. (2001) Gender Mainstreaming in Practice: The United Nations Transitional Assistance Group in Namibia. International Peacekeeping, 8, 97-110. http://dx.doi.org/10.1080/13533310108413898

[12] Preston, R (1997) Integrating Fighters after War: Reflections on the Namibian Experience, 1989-1993. Journal of 
Southern African Studies, 23, 453-472. http://dx.doi.org/10.1080/03057079708708550

[13] Saunders, C. (2009) Namibian Solidarity: British Support for Namibian Independence. Journal of Southern African Studies, 35, 437-454. http://dx.doi.org/10.1080/03057070902919967

[14] Nghiwete, V.N. (2009) An Autobiography of the Exile Child. Macmillan Publisher, Windhoek.

[15] Iipumbu, S. (2009) Children of the Liberation Struggle. SWAPO Party. http://www.swapoparty.org/children_of_the_liberation_struggle.html

[16] Shapanga, S. (2014) Namibia: NEKA Goes Head-to-Head With Struggle Kids. The Namibian Newspaper. http://allafrica.com/stories/201304230662.html

[17] Namibia Press Agency (2013) Namibia: “Struggle Kids”Arrested by Police. The Namibian Newspaper. http://allafrica.com/stories/201304171141.html

[18] Kakujaha, A. (2010) Namibia in Drive to Address the Plight of Struggle Children. The Southern Times Newspaper, 1213.

[19] Mamoc, M. (2005) The Social Determinants of Health Inequalities. Lancet, 365, 1099-1104. http://www.who.int/social_determinants/strategy/en/MarmotSocial\%20determinants\%20of\%20health\%20inqualities.pdf

[20] Warrington, M. (2005) Mirage in the Desert? Access to Educational Opportunities in an Area of Social Exclusion. Blackwell publishing, Oxford.

[21] Sheyavali, N. (2009) Struggle Kids Tell Their Tales. The Namibian Newspaper. http://www.namibian.com.na/index.php?section

[22] Reifsnider, E., Gallagher, B.C. and Forgione, M. (2005) Using Ecological Models in Research on Health Disparities. Journal of Professional Nursing, 21, 4216-4222. http://dx.doi.org/10.1016/j.profnurs.2005.05.006

[23] Rochat, T., Hough, A., Mitchell, A. and Jewitt, L. (2009) Working with Children, Families and Communities Affected by HIV\& AIDS, Conflicts, Poverty and Displacement in Africa. UNESCO, ESARO, Nairobi.

[24] Louw, D. and Louw, A. (2007) Child and Adolescent Development. University of the Free State, Bloemfontein.

[25] Mcilveen, P., Mcgregor-Bayne, H., Alcock, A. and Hjertum, E. (2004) Evaluation of a Semi-Structured Career Interview Derived from Systems Theory Framework. Australian Journal of Career Development, 12, 38-41. http://dx.doi.org/10.1177/103841620301200306

[26] Lawson, B. (1991) Pupil Discipline and Exclusion in Schools. Longman, London.

[27] Henning, E., Van Rensburg, W. and Smit, B. (2004) Finding Your Way in Qualitative Research. Van Schaik Publishers, Pretoria.

[28] Schutt, R.K. (2006) Investigating the Social World: The Process and Practice of Research. 5th Edition, SAGE Publications, London.

[29] David, M. and Sutton, C.D. (1997) Social Research: The Basics. Sage Publications, London.

[30] Zappulla, C. (1997) Suffering in Silence: Teachers with AIDS and the Moral School Community. Peter Lang Publication, Inc., New York.

[31] Babbie, E. (2004) The Practice of Social Research. Thomson Wadsworth, London.

[32] Creswell, J.W. (2008) Educational Research; Planning, Conducting, and Evaluating Quantitative and Qualitative Research. Pearson Education Publisher, New York.

[33] Mayer, C.H. (2008) Managing Conflict across Cultures, Values and Identities: A Case Study in South Automotive Industry. PhD Thesis, Rhodes University, Grahamstown.

[34] Patton, M.Q. (1990) Qualitative Evaluation and Research Methods. 2nd Edition, SAGE Publications, London.

[35] Keilly, M.K. (2009) Navigating Interdependence: How Adolescents Raised Solely by Grandparents Experience Their Family Relationships. Family Relations, 58, 162-175.

[36] Mwamwenda, T.S. (2004) Educational Psychology: An Africa Perspective. 3rd Edition, Heinemann Publishers, Sandton.

[37] Šileika, A., Rupšys, V. and Gruževskis, B. (2004) Youth Unemployment and Its Reduction Measures. Journal of Business Economics and Management, 5, 119-131.

[38] Mongudhi, T. (2013) Veteran Act Excludes Exile Kids. The Namibian Newspaper, 1-24. 